\title{
Word reading skill predicts anticipation of upcoming spoken language input: A study of children developing proficiency in reading
}

\author{
Nivedita Mani ${ }^{\mathrm{a}, *}$, Falk Huettig ${ }^{\mathrm{b}, \mathrm{c}}$ \\ ${ }^{a}$ Language Acquisition Junior Research Group, University of Goettingen, 37073 Goettingen, Germany \\ ${ }^{b}$ Psychology of Language Department, Max Planck Institute for Psycholinguistics, 6500 AH Nijmegen, The Netherlands \\ ${ }^{\mathrm{c}}$ Donders Institute for Brain, Cognition, and Behaviour, Radboud University Nijmegen, 6500 GL Nijmegen, The Netherlands
}

\section{A R T I C L E I N F O}

\section{Article history:}

Received 27 February 2014

Revised 15 May 2014

\section{Keywords:}

Anticipatory looking

Literacy

Reading

Speech processing

Orthographical representations

Language Acquisition

\begin{abstract}
A B S T R A C T
Despite the efficiency with which language users typically process spoken language, a growing body of research finds substantial individual differences in both the speed and accuracy of spoken language processing potentially attributable to participants' literacy skills. Against this background, the current study took a look at the role of word reading skill in listeners' anticipation of upcoming spoken language input in children at the cusp of learning to read; if reading skills affect predictive language processing, then children at this stage of literacy acquisition should be most susceptible to the effects of reading skills on spoken language processing. We tested 8 -year-olds on their prediction of upcoming spoken language input in an eye-tracking task. Although children, like in previous studies to date, were successfully able to anticipate upcoming spoken language input, there was a strong positive correlation between children's word reading skills (but not their pseudo-word reading and meta-phonological awareness or their spoken word recognition skills) and their prediction skills. We suggest that these findings are most compatible with the notion that the process of learning orthographic representations during reading acquisition sharpens pre-existing lexical representations, which in turn also supports anticipation of upcoming spoken words.
\end{abstract}

(c) 2014 Elsevier Inc. All rights reserved.

* Corresponding author.

E-mail address: nmani@gwdg.de (N. Mani). 


\section{Introduction}

The speed and accuracy of spoken language processing can be explained, at least in part, by the fact that mature (e.g., Altmann \& Kamide, 1999; DeLong, Urbach, \& Kutas, 2005; Federmeier \& Kutas, 1999; Kamide, Altmann, \& Haywood, 2003; Van Berkum, Brown, Zwitserlood, Kooijman, \& Hagoort, 2005; Wicha, Moreno, \& Kutas, 2004) and developing (e.g., Borovsky, Elman, \& Fernald, 2012; Mani \& Huettig, 2012; Nation, Marshall, \& Altmann, 2003) language users are able to anticipate upcoming linguistic input based on constraints set by available visual and auditory information. For instance, on hearing the verb eat in a sentence such as "The boy eats the big cake," listeners anticipate that the direct object is likely to be something edible and use this to fixate an image of an edible object such as cake in preference over an inedible object. Despite the evidence in favor of such efficient language processing across a variety of populations (toddlers, children, and adults), a growing body of research finds substantial individual differences in both the speed and accuracy of spoken language processing potentially attributable to participants' literacy skills (e.g., Adrian, Alegria, \& Morais, 1995; Huettig, Singh, \& Mishra, 2011; Kosmidis, Tsapkini, Folia, Vlahou, \& Kiosseoglou, 2004; Lukatela, Carello, Shankweiler, \& Liberman, 1995; Mishra, Singh, Pandey, \& Huettig, 2012; Morais, Cary, Alegria, \& Bertelson, 1979; Petersson, Reis, Askelof, Castro-Caldas, \& Ingvar, 2000; Reis \& Castro-Caldas, 1997; Reis, Petersson, Castro-Caldes, \& Ingvar, 2001; Serniclaes, Ventura, Morais, \& Kolinsky, 2005; Silva, Faísca, Ingvar, Petersson, \& Reis, 2012). The current study examined the contributions of two potential reasons for such an effect of literacy on spoken language processing: (a) increased granularity of phonological processing through learning to decode an orthographic code and (b) sharpening of pre-existing lexical representations through acquisition of orthographic representations for words. Against this background, the study took a renewed look at the role of reading skill in listeners' anticipation of upcoming spoken language input in children at the cusp of literacy acquisition. In what follows, we first provide a brief review of previous studies examining the influence of literacy on both adult and child spoken language processing before outlining the current study.

A number of studies have compared phonological processing skills in illiterate and literate adults and found important differences between the populations in tasks involving phonological awareness, pseudoword repetition, and phonological word-object mapping. For instance, Morais and colleagues (1979) asked illiterates and late literates (who had taken part in adult literacy programs after 15 years of age) to add or delete one phoneme (e.g., /p/) of a spoken word and found poorer performance for illiterates than for literates on non-word trials. Performance on non-word trials is critical here because performance on real-word trials can be influenced by participants' retrieving pre-existing representations of these words. This is especially so because illiterates have been found to perform as well as literates in real-word repetition tasks (Reis \& Castro-Caldas, 1997) while performing worse than illiterates in repeating pseudo-words (Reis \& Castro-Caldas, 1997). This finding is typically explained by suggesting that illiterates have impaired processing at the level of sub-lexical phonological structure (Petersson et al., 2000).

More information yet is provided by studies employing online methods that offer an opportunity to measure phonological processing with fine temporal sensitivity. For instance, Huettig and colleagues (2011) examined low and high literates' use of phonological information in an online eye-tracking task. Here, participants listened to simple spoken sentences such as "Today he saw a crocodile" while they looked at a visual scene of four objects. The authors observed that low literates, unlike high literates, do not exploit phonological matches between spoken words and visual referents for languagemediated visual orienting in an efficient manner. In modeling this behavior, Smith, Monaghan, and Huettig (2013) concluded that literacy acquisition results in changes to the grain size of phonological mappings. This conclusion was supported by their findings that models containing more specified phonological representations (representation of individual phonemes) behaved similarly to the high literates, whereas models containing less specified representations (specification at the word level alone) performed similarly to the low literates.

Similarly, recent work also suggests that low literates are worse at anticipating upcoming spoken linguistic input relative to high literates (Mishra et al., 2012). Here, participants were presented with a visual display of four objects-for instance, a door (target) along with a button, a flower, and a drum 
(unrelated distracter objects)-and heard a sentence whose adjective semantically (and syntactically) constrained the possible nouns that could be considered a thematic fit to the adjective, for instance, "Now, you are going to see a tall ... door," where only the object label door (but not the distracter object names) was an appropriate thematic fit to the adjective tall. Whereas high-literate adults shifted their gaze toward the semantically appropriate object soon after the onset of the constraining adjective, low-literate adults shifted their gaze to the target (door) only on hearing the disambiguating noun, that is, door.

However, because most of the studies reviewed above have compared processing in literate and illiterate adults, their results are subject to discussion of the social reasons behind one group being unable to read, typically due to poverty, child labor, and/or access to schooling. In contrast, observing the correlation between children's developing reading skills and their performance in language-based tasks allows investigation of the individual differences in processing and may provide more information as to individual-specific reasons why reading acquisition interacts with performance in a particular task.

As in the adult literature, research into children's reading development provides strong support for a link between phonological awareness and reading skills. Thus, children's performance on phonological awareness tasks accounts for much of the variability in their reading skills even after controlling for their age and IQ levels (for reviews, see Brady \& Shankweiler, 1991; Goswami \& Bryant, 1990; Hatcher, Hulme, \& Ellis, 1994; Mann \& Liberman, 1984; Wagner \& Torgesen, 1987). This conclusion is supported by findings that (a) word-level decoding skills are important to reading development (Juel, Grifflth, \& Gough, 1986) and (b) such word-level decoding skills are themselves dependent on participants' phonological abilities (Wagner, Torgesen, \& Rashotte, 1994). These findings have been interpreted as either attributing a causal role to phonological awareness in literacy acquisition (e.g., Goswami, 1993; Goswami \& Bryant, 1990; Gough \& Hillinger, 1980) or vice versa, that is, that literacy acquisition, especially participants' ability to decode written information, helps listeners to better analyze speech input (Morais, Castro, \& Kolinsky, 1991; Morais, Castro, Scliar-Cabral, Kolinsky, \& Content, 1987).

Furthermore, recent work shows that children with larger spoken language repertoires are more able to anticipate upcoming language input (Mani \& Huettig, 2012). This is in line with the view that anticipation of upcoming language input is facilitated by additional production representations speeding recognition of the upcoming input (e.g., Chang, Dell, \& Bock, 2006; Dell \& Chang, 2013; Pickering \& Garrod, 2007). Extending this to an influence of orthography on spoken language processing, it is possible that orthographic representations of known words may speed recognition of these words so as to facilitate anticipation of upcoming language input. In this case, learning to read may influence spoken language processing such that the more and better a child can read, the more information the child is able to retrieve from the corresponding lexical representation and the better the child can anticipate spoken language input. In other words, orthography exposure equips speakers with additional representations of their spoken language repertoire that might lead to lexical representations being more easily available to, and thus more easily recognized by, literate language users. Similar arguments have been raised to explain the influence of orthography on phonological processing (Frost \& Katz, 1989; Pattamadilok, Perre, Dufau, \& Ziegler, 2009; Seidenberg \& McClelland, 1989; Ziegler \& Ferrand, 1998). According to this explanation, participants' anticipation of upcoming spoken language input should be affected not by their ability to decode written input but rather by their ability and the speed with which they access stored written word forms.

Indeed, a link between participants' oral language skills and reading development is suggested by recent work (Kendeou, van den Broek, White, \& Lynch, 2009) suggesting that phonological awareness and oral language skills both make separable contributions to the development of children's reading abilities. It would be interesting to see, therefore, the extent to which our online measure of children's oral language skills-that is, children's anticipation of upcoming language input-can predict their reading proficiency.

In talking about children's reading skills, however, it is important that we distinguish between phonologically mediated decoding of orthographically presented words and proficient reading of whole words. The literature on the development of word reading skills proposes that children may either break down words based on grapheme-phoneme relations or employ a logographic strategy 
(otherwise known as the visual or global strategy) where they read whole words as logograms (Goswami \& Bryant, 1990). Furthermore, a number of studies suggest that children rely quite substantially on visual word reading (Barron \& Barron, 1977; Kimura \& Bryant, 1983; see Goswami \& Bryant, 1990, chap. 2, for an extensive review of studies documenting this finding) from early on; even 6-year-old beginning readers are able to read words without relying on grapheme-phoneme translations such that English children, for instance, often read words in the same way as Japanese children read kanji.

However, it is likely that lexical access through phonological decoding may play a more important role during the early stages of reading acquisition (Doctor \& Coltheart, 1980; Ehri \& Wilce, 1979), although factors such as readers' familiarity with the words and the transparency of a language's orthography strongly influence the extent of whole-word reading in children. Thus, for instance, in learning to read unfamiliar or new words, children resort to making analogies with familiar words based on sub-lexical units such as onsets and rimes (Bryant \& Bradley, 1980; Goswami \& Bryant, 1990). Thus, as with the studies on adult illiterates, Bryant and Bradley (1980) concluded that children are more likely to turn to grapheme-phoneme relations when reading non-words relative to real words. Similarly, studies with children learning English suggest that children perform much better when reading real words relative to non-words, suggesting a reliance on whole-word reading in this population; were children to read words solely through phonologically mediated "sub-word translation processes," there should be little difference between their reading of real words and non-words (Bruck, Genesee, \& Caravolas, 1997; Frith, Wimmer, \& Landerl, 1998).

\section{The current study}

Against this background, the current study examined children during their second year of reading acquisition on anticipation of upcoming spoken language input and correlated their performance in the anticipation task to two measures of reading skills: their ability to read real words and their ability to read pseudo-words. The contrast between children's performance in these tasks, we suggest, provides an index of the extent to which children rely on whole-word recognition in the reading of familiar words. The latter in turn informs us of the extent to which lexical knowledge, and more generally reading skills as a proxy for language experience, affects children's performance in the anticipation task. Any correlation between children's anticipation of upcoming spoken language input and their real-word reading skills would be consistent with the suggestion that becoming literate endows children with additional orthographic representations of known words that speed their processing of spoken language input. Thus, by contrasting children's ability to read real words and pseudo-words, we attained separate measures of the extent to which children's decoding skills versus children's language experience affects their anticipation of spoken language input.

Children were tested toward the end of their second year of schooling when they had 2 years of experience in learning to read and write. By this stage, most German children can read words out loud quite quickly and accurately irrespective of whether they have encountered the words before. German-speaking children at this age move gradually, but quite rapidly, to whole-word recognition during reading. Children learning to read transparent languages such as German are able to master the phonics method to reading relatively quickly. Indeed, children learning to read more transparent languages perform better in non-word reading tasks relative to children learning to read English (German: Frith et al., 1998; Italian: Cossu, Gugliotta, \& Marshall, 1995). There is, however, still considerable variability in their reading skills. For instance, children tested in the current study could read out loud an average of 41 words within 1 min, ranging between 19 and 87 words. It is this variability that the current study wished to examine in correlation with children's anticipation of upcoming linguistic input in spoken language processing.

We presented children with the same task as in Mani and Huettig (2012); children were shown a visual display containing two familiar objects, such as a cake and a bird, and heard the sentence "Der Junge isst den großen Kuchen" (The boy eats the big cake) as we tracked their eye movements across the visual display (anticipation task). Following this task, as in similar studies examining the correlation between children's language proficiency and their reading abilities (see, e.g., Nation \& Snowling, 1998a, 1998b; Perfetti, Goldman, \& Hogaboam, 1979), children were tested on their phonological 
awareness (syllable detection and "syllable pointing"), their pseudo-word decoding skills (pseudoword reading), and their experience in reading (real word reading). In addition, children were also tested on their recognition of known familiar words in a visual world paradigm (naming task) to examine the extent to which these factors interacted with children's language processing and word recognition per se.

\section{Method}

\section{Participants}

A total of 46 German 8-year-olds participated in the experiment ( $M=8$ years 4 months, range $=$ 8 years 0 months to 8 years 11 months, 28 boys and 18 girls). Of these, data from three children could not be included in the final analysis due to either problems with calibration or data loss. All children spoke German primarily at home (four children also spoke a second language less than $30 \%$ of the time). Children had normal or corrected-to-normal vision $(n=4)$ and had no hearing problems.

\section{Stimuli}

\section{Anticipation task}

Stimuli for the anticipation task consisted of 24 8-s videos, of which each child received 12. Each video began with the presentation of two images of familiar objects side by side on the screen followed by a sentence containing either a semantically constraining or semantically neutral verb related to one of the images on the screen. For instance, children saw a picture of a cake (Kuchen) and a bird (Vogel) and heard either a sentence containing a semantically constraining verb ("The boy eats the big cake") or a sentence containing a neutral verb ("The boy sees the big cake"). The pictures remained onscreen for $8 \mathrm{~s}$. Fig. 1 presents a schematic of the trials in the current study. The auditory stimuli were presented such that the onset of the verb was $3000 \mathrm{~ms}$ into the trial. Furthermore, we ensured that there was at least 1500 ms between the onset of the verb and the onset of the disambiguating noun (i.e., the target label Kuchen [cake]) in each of the sentences. Thus, the earliest onset of the noun during the trials was at $4500 \mathrm{~ms}$. There was no linguistic information interspersed between the verb and the noun that could bias children toward any one of the pictures on-screen (see Mani \& Huettig, 2012, for a more extensive discussion of the stimuli and paradigm).

Speech stimuli were produced by a female native speaker of German. The videos measured $1280 \times 1024$ pixels, with the two images equally spaced across this area to the left and right sides of the video. Each image measured $340 \times 480$ pixels, with a separation of 160 pixels between the edges of each image. Location of the images was counterbalanced so that targets appeared equally often to the left and right across videos. Labels for the target and distracter images were semantically and associatively unrelated. Target and distracter pairings were maintained and appeared in the semantically constraining and neutral videos with equal frequency. That is, half of the children saw six targets in semantically constraining trials, whereas the other half saw the same six targets in neutral trials. Half of the videos presented children with sentences containing semantically constraining

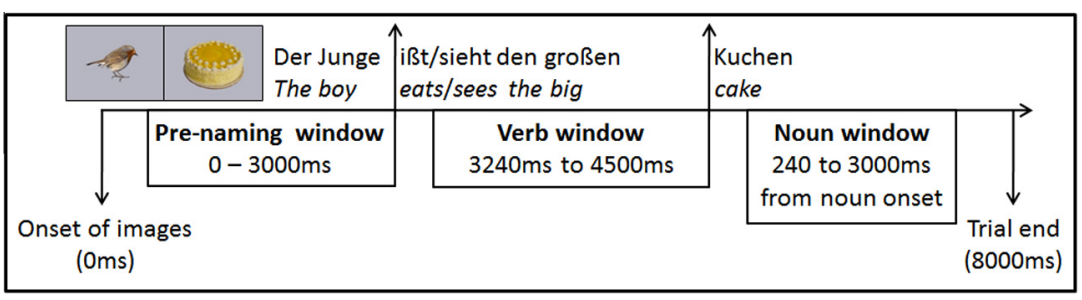

Fig. 1. Schematic of trials presented to children in the current study. 
verbs, whereas the other half presented children with sentences containing neutral verbs (see Mani \& Huettig, 2012, for a list of stimuli).

\section{Naming task}

Stimuli for the naming task consisted of eight videos, each of $8 \mathrm{~s}$ duration. Each video began with the presentation of four images of familiar objects on the screen, followed by the auditory presentation of an isolated word token. For instance, children saw an image of a hairbrush, a bicycle, a pizza, and a shoe and heard the word Bürste (hairbrush) halfway through the video, with the onset of the word beginning at $4 \mathrm{~s}$. Speech stimuli were produced by a female native speaker of German. The videos measured $1280 \times 1024$ pixels, with images appearing at the top left, top right, bottom left and bottom right of the screen. Each image measured $340 \times 480$ pixels. Location of the images was counterbalanced so that targets appeared equally often in each of the locations across videos.

\section{Procedure}

Videos were presented in the middle of a 40 -inch screen located immediately above the eyetracker. Children sat in a height-adjustable chair approximately $100 \mathrm{~cm}$ away from the screen. During the experiment, gaze data from both eyes were recorded using a Tobii X120 eye-tracker. The eyetracker records gaze data at $120 \mathrm{~Hz}$ with an average accuracy of $0.5^{\circ}$ visual angle. The Tobii Studio package was used to present the videos to the children during the experiment. Prior to testing, we calibrated the gaze of each child using a nine-point calibration procedure in which an attention-getter appeared in every position of a $3 \times 3$ grid of calibration points. The experiment started if eight or more points were successfully calibrated for at least one of the eyes.

\section{Anticipation task}

Each child was presented with 12 of the 24 videos from the stimulus set such that each child received six semantically constraining trials and six semantically neutral trials. The onset of the verb and noun in the videos divided the trials into a pre-verb phase, a verb phase, and a noun phase. Children saw each video only once during the anticipation task, with no repetition of auditory or visual stimuli across videos.

\section{Naming task}

Immediately following the anticipation task, children were presented with the videos for the naming task. Children saw each video only once during the naming task, with no repetition of auditory or visual stimuli across videos.

\section{Phonological awareness task}

Children's phonological awareness was tested using a two-part syllable detection task of the Entwicklungstest Sprache für Kinder von 4 bis 8 Jahren (ETS-4 to 8; Language Development Test for Children standardized for children between 4 and 8 years of age inclusive). Here, children were presented with a familiar image and first asked to label the image. This image was divided into as many parts as the number of syllables in the label, and children were asked to clap out the individual syllables; for instance, they saw a picture of a camel (Kamel) and were then shown the camel divided into two halves and asked to clap out the name, that is, clap two times, once saying "Ka" out loud and the second time saying "mel" out loud. The instructions given to children were to speak out the individual parts of the word and clap along ("Sag mir jetzt die Teile und klatsche dabei"). Next, children were asked to point to one of the parts of the image while saying out loud the corresponding syllable. For instance, children were asked to point to the part corresponding to mel (i.e., the second half of the image) while saying "mel" out loud. Children were given a score of having correctly responded only if they divided the word into its constituent syllables correctly (in the first part of the task) and pointed to the right part of the image (in the second part of the task). Children were given a practice session with three words that did not count toward their score. During the practice session, the experimenter would provide feedback (as instructed by the ETS-4 to 8) and clap along with children. Scores were then converted to normally distributed percentage scores based on the ETS- 4 to 8 tables. 
Reading skills

Children's reading skills were tested using the Salzburger Lese und Rechtschreibtest II (SLRT-II; Salzburger Reading and Spelling Test II) standardized for children in school years 1 to 6 of school (children tested in the current study were in school year 2). Here, children were tested on the number of words and non-words they could correctly read out loud within $1 \mathrm{~min}$ from a sheet of paper containing 156 words and 156 non-words (in separate sheets of paper). Words were counted as being correctly read out loud only if children pronounced the words correctly on the first attempt. Children were told to read the words out loud from top to bottom as quickly as possible without making a mistake and were given an initial practice session before proceeding to the main task (using the instructions provided by the SLRT-II). For the non-word reading task, children were told that the list contained words that did not exist but could, nevertheless, be spoken out loud (as according to the SLRT-II). In both tasks, children were told that they did not need to read out loud all of the words but to continue until the experimenter said "Stop" (when $1 \mathrm{~min}$ was over). The final scores given to children were calculated from the difference between the number of words they read out loud correctly and the number of words they read out loud incorrectly within $1 \mathrm{~min}$ (Correct - Incorrect).

\title{
Data analysis
}

Areas of interest were defined according to the size of the individual images ( $480 \times 340$ pixels) and their location on screen. The eye-tracker provides an estimate of where children were looking at each time stamp during the trial, with one data point approximately every $8 \mathrm{~ms}$. Data from time stamps were included only when the eye-tracker reliably acquired data from one or both eyes of participants (validity less than 2 on the Tobii scale). Gaze data from the eye-tracker were aggregated into 40-ms bins such that each 40 -ms bin was coded for whether children were looking at the target or the distracter. These bins were further aggregated into three time windows.

\section{Anticipation task}

The first window, the pre-verb window, included all fixations from the onset of the trial to the onset of the verb at $3000 \mathrm{~ms}$ into the trial. The second and critical window, the verb window, included all fixations that occurred between $240 \mathrm{~ms}$ after the onset of the verb and the onset of the disambiguating noun (individually calculated for each verb-noun pair). The third time window, the noun window, included all fixations that occurred between 240 and $3000 \mathrm{~ms}$ after the onset of the noun. The 240-ms lag ensured that only eye movements during this time period can reliably be interpreted as a response to a particular auditory stimulus (cf. Saslow, 1967). For each window, we determined the amount of time children looked at the target and distracter and calculated the proportion of fixations to the target and distracter in each of these three time windows. This proportion of the looking time measure was our dependent variable in the analysis reported below.

\begin{abstract}
Naming task
Fixations were divided into two windows: a pre-naming window and a post-naming window. The pre-naming window included all fixations from the onset of the trial to the onset of the target word (i.e., from 0 to $4000 \mathrm{~ms}$ ). The post-naming window included all fixations $240 \mathrm{~ms}$ from the onset of the target word to the end of the trial (4240-8000 ms). For each window, we determined the amount of time children looked at the target and the three distracters and calculated the proportion of fixations to the target object in each of these two time windows. This proportion of the looking time measure was our dependent variable in the analysis reported below.
\end{abstract}

\section{Results}

\section{Anticipation task}

A $3 \times 2$ within-participants analysis of variance (ANOVA) with the factors window (pre-verb, verb, or noun window) and condition (semantically constraining or semantically neutral) found a significant 


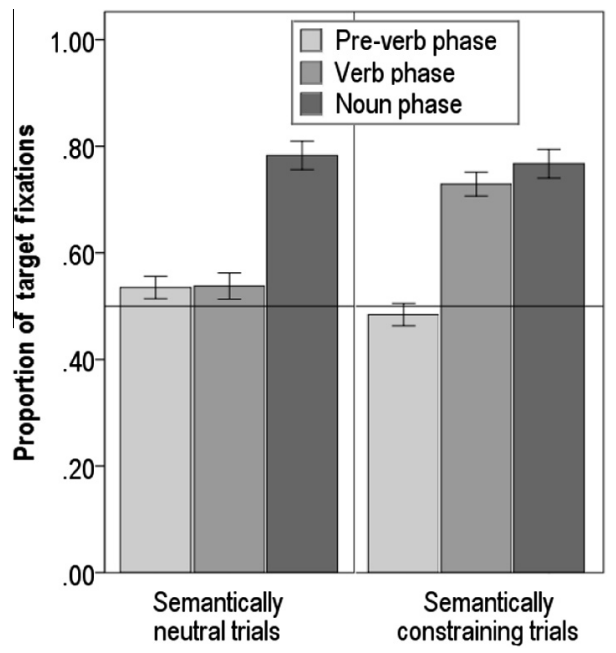

Fig. 2. Proportions of target fixations in pre-verb window (0-3000 ms), verb window (3240 to onset of noun), and noun window (onset of noun to $3000 \mathrm{~ms}$ following onset of noun) in semantically constraining and neutral trials.

main effect of window, $F(1,42)=70.48, p<.001, \eta_{\mathrm{p}}^{2}=.63$, a significant main effect of condition, $F(1,42)=7.98, p=.007, \eta_{\mathrm{p}}^{2}=.16$, and a significant interaction between window and condition, $F(2,84)=12.38, p<.001, \eta_{\mathrm{p}}^{2}=.23$. Figs. 2 and 3 plot the proportion of target fixations in semantically constraining and neutral trials in each of the three windows across the course of the trial (Fig. 2) and the proportion of target fixations across the course of the verb and noun windows (Fig. 3). As is clear from Fig. 3, shortly after the onset of the verb, the proportion of target fixations in semantically constraining and neutral trials deviates from one another even before the earliest onset of the disambiguating noun.

Planned post hoc comparisons examined whether there was a change in children's target fixations from the pre-verb window to the verb window and from the pre-verb window to the noun window separately for each condition. An increase from the pre-verb window to the verb window in the semantically constraining condition can be interpreted as evidence that children predict upcoming linguistic input in spoken language processing and use this information to fixate thematically appropriate objects on hearing a semantically constraining verb even before hearing the label for this object. Indeed, as with the 2-year-olds tested in Mani and Huettig's (2012) study, there was a significant increase in children's fixations to the target from the pre-verb window to the verb window in semantically constraining trials, $t(42)=-7.82, p<.001$, but not in semantically neutral trials, $t(42)=-.08, p=.93$. In keeping with these findings, there was a significant difference in target fixations in the verb window between semantically constraining and non-constraining trials, $t(42)=-5.51, p<.001$, but not in the noun or pre-verb win$\operatorname{dow}(p s>.10)$.

There was also a significant increase in children's fixations to the target from the pre-verb window to the noun window in both semantically constraining trials, $t(42)=-9.33, p<.001$, and semantically neutral trials, $t(42)=-8.14, p<.001$. Unsurprisingly, on hearing the disambiguating target label (e.g., Kuchen [cake]), children fixated the target image in both semantically constraining and neutral trials.

\section{Naming task}

Next, we analyzed children's performance in the naming task. A paired samples $t$ test found that children looked significantly longer at the target during the post-naming phase $(M=45 \%)$ relative to the pre-naming phase $(M=28 \%)$ in naming trials, $t(41)^{1}=-6.65, p<.001$.

\footnotetext{
${ }^{1}$ One participant did not complete the naming task and is not included in any comparisons using the naming task. Excluding this participant from the other tasks does not change the pattern or significance of the results.
} 


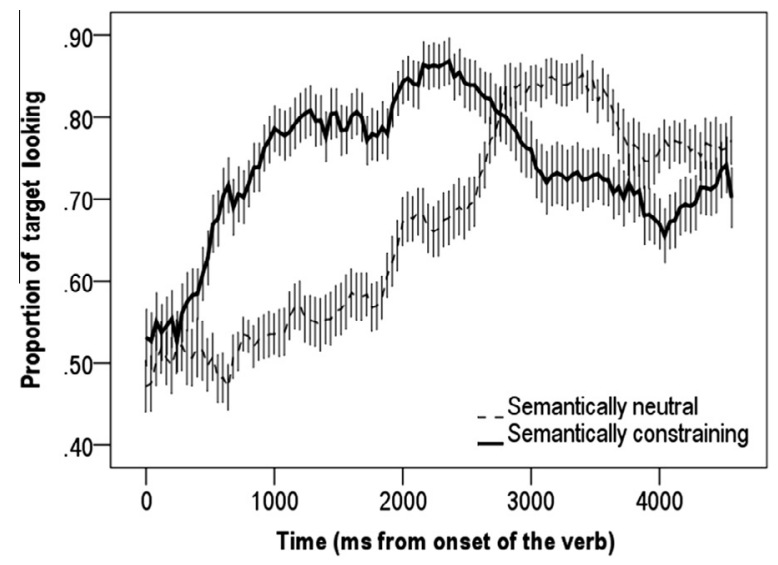

Fig. 3. Proportions of target fixations from the onset of the verb in semantically neutral and semantically constraining trials. Fixations to the target increase in semantically constraining trials shortly after the onset of the constraining verb.

\section{Phonological awareness tasks}

The phonological awareness task consisted of two parts. In the first part, children were asked to divide a word into its constituent syllables (having been told how many syllables to divide a word into, e.g., "Divide Kamel into two parts"). There was little variability in children's performance in this task, with children correctly dividing the word into the appropriate syllables in nearly all trials $(M=18.95$ of 19 trials, range $=18-19$ ). In the second half of this test, children were asked to identify the position of a syllable within a word, e.g., "Is mel the first or second part of the word Kamel?") There was more variability in children's performance in this task $(M=16.6$ of 19 trials correct, range $=13-19)$.

\section{Reading tasks}

In the word reading task, we measured the number of words that children could correctly read out loud from a list of words in less than $1 \mathrm{~min}$. The mean number of real words that children could read out loud was 49.86 ( $S D=19.26$ ), ranging from 19 to 87 words read out loud in less than 1 min across the children tested. In the non-word reading task, we measured the number of non-words that children could correctly read out loud from a list of non-words in less than $1 \mathrm{~min}$. The mean number of non-words that children correctly read out loud was 32.08 ( $S D=8.36$ ), ranging from 19 to 53 nonwords read out loud in less than 1 min across the children tested. A paired samples $t$ test confirmed that children performed better at the real-word reading task than at the non-word reading task, $t(42)=-9.42, p<.001$.

\section{Performance across tasks}

We then compared children's performance in the anticipation task against their performance in the other tasks (i.e., phonological awareness tasks, reading tasks, and naming task). We ran a stepwise multiple regression to investigate the individual contribution of children's performance in the real-word and non-word reading tasks. In this model, predictors are added or removed from the regression equation based on the predictive value of the different variables. Children's performance in the phonological awareness tasks, reading tasks, and naming task were all included as predictors in the analysis, with the difference between looking time at the target in the verb window across semantically constraining and neutral trials as the dependent variable. The most accurate fit was obtained by retaining only children's real-word reading scores as a predictor of performance, $F(1,41)=9.01, p=.005, R^{2}=18 \%$, while rejecting all other measures (including performance in the phonological awareness tasks). According to the regression equation, a unit change in children's 
real-word reading scores produces a change of .42 in the $z$ score of the prediction effect. Thus, only children's real-word reading scores were a worthwhile predictor of children's prediction skills. Fig. 4 plots children's performance in the real-word reading task against the increase in target fixations from the pre-verb window to the verb window in semantically constraining trials.

Note that children's performance in the real-word reading task was correlated with performance in the non-word reading task $(r=.85, p<.001)$. To further disentangle the role of real-word and pseudoword reading skills in children's anticipation of upcoming language input, we analyzed whether children's real-word reading skills correlate with their performance in the anticipation task once the shared variation between real-word reading scores and pseudo-word reading scores has been partialled out. The residualized real-word reading scores refers to the amount of variability in real-word scores that is left over after accounting for the variability explained by children's pseudo-word reading scores. Using the residuals output by regressing real-word scores with pseudo-word reading scores, we found a correlation between residualized real-word scores and children's performance in the anticipation task $(z=.33, p=.028)$. This finding suggests that there is a component to children's anticipation of upcoming language input that is specifically tied to their real-word reading skills and not their pseudo-word decoding skills.

Next, we examined the possibility that children who performed better in the anticipation task and the visual word decoding task were, in general, more advanced language users by comparing skilled and less skilled readers' performance in the naming task. Both skilled readers, $t(20)=-4.92$, $p<.001$, and less skilled readers, $t(20)=-4.49, p<.001$, showed an increase in target looking from the pre-naming phase to the post-naming phase in the naming task, and there was no significant difference in the naming effect (difference in target fixations from the pre-naming phase to the postnaming phase) across skilled and less skilled readers, $t(40)=0.46, p=.45$. Indeed, if anything, the less skilled readers showed a numerically larger naming effect $(M=.18)$ relative to the skilled readers $(M=.14)$.

Finally, to analyze the relationship between performance in the anticipation task and children's realword reading skills further, we divided participants into two groups, less skilled readers and skilled readers, according to the median split in their real-word reading scores to compare their performance in the anticipation task. Both groups showed a significant increase in fixations to the target from the preverb window to the verb window in semantically constraining trials [skilled readers: $t(20)=-6.91$, $p<.001$; less skilled readers: $t(21)=-4.46, p<.001$ ] but not in semantically neutral trials $(p s>.20)$. Similarly, both groups showed greater looking toward the target in the verb window in semantically constraining trials relative to neutral trials: skilled readers, $t(20)=-5.91, p<.001$; less skilled readers, $t(21)=-2.23, p=.026$. However, the difference in target fixations in the verb window between

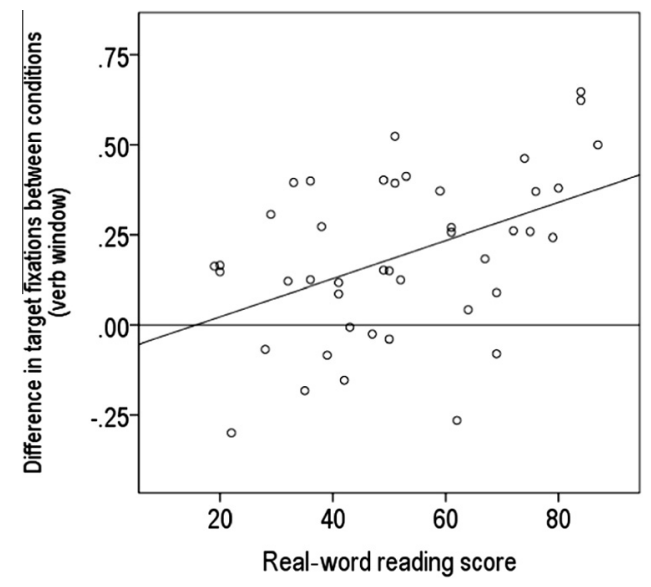

Fig. 4. Correlations between difference in target fixation in semantically constraining trials and neutral trials (in verb window) and children's reading performance (number of words correctly read out loud). 
semantically constraining and neutral trials was greater in skilled readers relative to less skilled readers, $t(41)=-3.02, p=.004$. Fig. 5 plots the proportion of target fixations in semantically constraining and neutral trials in each of the three windows separately for skilled and less skilled readers.

\section{General discussion}

The current study set out to examine the contribution of children's literacy skills to their anticipation of upcoming language input. In examining this possibility, we found that 8-year-olds with recent exposure to literacy were able to predict upcoming input in spoken language processing and use this information to direct their eye gaze toward thematically appropriate objects. Crucially, however, their ability to predict upcoming input in spoken language processing was closely bound to their real-word reading skills but not to their pseudo-word reading and phonological awareness. Across different analyses, performance in the real-word reading task interacted significantly with children's performance in the prediction task; those children who could read real words better and faster were more able to predict upcoming linguistic input and use this to fixate thematically appropriate objects soon after the onset of the semantically constraining verb. Thus, within the context of children growing up in the same area with similar exposure to literacy (i.e., a similar number of years of schooling), the findings of the current study provide further support for the notion of an interaction between children's literacy skills, specifically their real-word reading skills, and their oral language proficiency, specifically their anticipation of upcoming spoken language input.

Why might real-word reading skills have an impact on participants' prediction of upcoming language input? One oft-mentioned possibility is that orthographic exposure has an impact on the granularity of phonological processing such that participants who can read have more fine-grained phonological representations of words, which in turn improves their prediction of upcoming language input. According to this possibility, participants' prediction skills should correlate with their phonological awareness as well as their pseudo-word reading skills. We suggested that participants' reading of pseudo-words provides a more appropriate measure of their decoding skills per se (see also Wagner \& Torgesen, 1987) because frequent real words could be read out loud without access to phonological information (Coltheart, 1978; Seidenberg, Waters, Barnes, \& Tanenhaus, 1984). However, the current study found no significant impact of children's decoding of pseudo-words and their phonological awareness on their prediction abilities and, therefore, lends little support to the notion that improved speech processing (i.e., improved prediction of upcoming linguistic input) is causally related to participants' decoding skills and phonological awareness. We note, however, that the phonological tasks

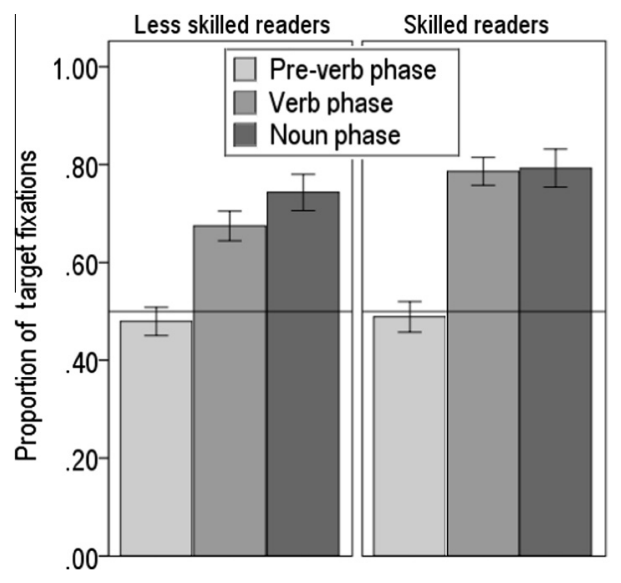

Fig. 5. Proportions of target fixations in pre-verb window (0-3000 ms), verb window ( 3240 to onset of noun), and noun window (onset of noun to 3000 ms following onset of noun) in semantically constraining and neutral trials, separated according to reading skill. 
employed in the current study manipulated segments above the phoneme level and that it would remain interesting to examine whether phonemic awareness affects children's anticipation of upcoming language input. Nevertheless, given that children's non-word reading skills did not correlate with their anticipation of upcoming language input, we suggest that a decisive role for purely phonemic awareness is unlikely.

An alternate possibility is that learning to read equips readers with sharpened or more detailed lexical representations through acquisition of orthographic representations for the words they know. According to this argument, the current results can be explained by suggesting that orthographic representations of auditorily presented words are co-activated during spoken language perception and boost recognition of auditorily presented words. In particular, co-activated orthographic representations sharpen children's lexical representations of these words such that children are able to quickly retrieve information associated with these words, which in turn enables their prediction of information thematically consistent with these words. Some evidence in support of this hypothesis comes from the finding that children's real-word reading skills, but not their pseudo-word reading skills, correlated with their prediction ability. We suggest, therefore, that familiarity with a word, as in the case of the frequent real words used in the real-word reading test and the stimuli in the current study, helps children to automatically retrieve the orthographic form of the word. This automatic retrieval of the orthographic forms of words improves children's performance in both the real-word reading task and the prediction task (according to the mechanisms suggested above).

However, we note that because these conclusions are not drawn from longitudinal data, it is difficult to assess the direction of causation in the link between children's real-word reading skills and their anticipation of upcoming language input. It is likely that, indeed, improved anticipation of upcoming language input facilitates the process by which children learn to read words such that children who can better anticipate upcoming language input (and have better oral language skills) become better readers (cf. Kendeou et al., 2009). Similarly, it is possible that children's anticipation of upcoming language input and their reading proficiency may be influenced by increased oral language proficiency overall rather than merely by their receptive vocabulary skills. Thus, for instance, children with increased syntactic grammatical skills may be better able to anticipate upcoming language input, and their increased oral language proficiency may also affect their reading proficiency. Longitudinal studies, we suggest, would be an ideal next step to capture the direction of causation of these findings. In the absence of such longitudinal findings, the current study concludes, as noted above, merely in favor of an interaction between children's literacy skills, specifically their real-word reading skills, and their oral language proficiency, specifically their anticipation of upcoming spoken language input.

Relatedly, it is possible that reported correlations between word reading skills and anticipation reflect underlying differences in the vocabulary knowledge of the children being tested. ${ }^{2}$ Thus, it is possible that the skilled readers had larger vocabularies and that this was principally responsible for their improved performance in both the real-word reading task and the anticipation task. Indeed, a number of studies find positive correlations between children's vocabulary size and their prediction skills as early as 2 years of age (Mani \& Huettig, 2012) and older (Borovsky et al., 2012; but see Nation et al., 2003) such that one might conclude that children's real-word reading skills and their anticipation of upcoming language input both are measures of children's advanced vocabulary skills or are influenced by children's advanced vocabulary skills. We note that this does not conflict with our explanation for the correlation between word reading skills and language performance reported above. Indeed, we strongly believe that advanced reading skills are merely a stand-in for improved language experience and improved experience in reading familiar words, of which increased vocabulary knowledge is a characteristic feature.

A further related possibility is that the additional experience garnered through reading is likely to be an important reason for the relationship between literacy and anticipatory processing. Literacy, we argue, may be a proxy for language experience and, specifically, experience in reading familiar words. Given that the low-skilled readers in the current study may find reading more challenging than the high-skilled readers, the former group may have less experience in reading and, consequently, have

\footnotetext{
${ }^{2}$ Note that we could not provide an independent measure of children's vocabulary knowledge given that the German version of the Peabody Picture Vocabulary Test is standardized for use only with children over 13 years of age.
} 
less exposure to statistical co-occurrences between words (cf. McDonald \& Shillcock, 2003) and/or to the contextual knowledge gained through reading (cf. Schwanenflugel \& Shoben, 1985). In other words, enhanced reading experience may provide the high-skilled readers with more opportunities to learn to read words and the semantic or contextual associations between words. These words may then cluster together in neighborhoods, enabling speeded recognition of words from dense contextual neighborhoods (Buchanan, Westbury, \& Burgess, 2001; Mirman \& Magnuson, 2009) or speeded retrieval of words related to previously presented semantically or associatively related words, as required in the anticipatory looking task (cf. Arias-Trejo \& Plunkett, 2009; Mani, Durrant, \& Floccia, 2012; and Styles \& Plunkett, 2011, for studies with young children). Indeed, an interesting finding of the current study is that prediction skills were correlated significantly with real-word reading speed but not with pseudo-word reading speed and syllable awareness. This might suggest that word decoding skills per se do not solely underlie children's prediction of upcoming spoken language input and supports the explanation that children's experience with reading known words influences the differences found in the current study.

Relatedly, the correlations with word reading skills found here might themselves be caused by the possibility that skilled word readers are skilled reading comprehenders and that it is children's skill in reading comprehension that underlies the reported correlation between reading skill and anticipation found in the current study. This suggestion is supported by work examining contextual facilitation in reading across three populations-dyslexics, poor comprehenders, and normal readers-in an attempt to differentiate between effects of word decoding and reading comprehension (Nation \& Snowling, 1998a, 1998b; see also Gough \& Tunmer, 1986). By controlling in this way for decoding and comprehension skills, this work found that dyslexics benefit from contextual information as compensation for their poor decoding skills, whereas poor comprehenders failed to benefit from contextual information as much as normal comprehenders. This suggests an important role for reading comprehension in predicting participants' use of contextual facilitation in a reading task. However, although it is possible that reading comprehension underlies the correlation found in the current study, it is equally possible that reading comprehension affects participants' performance in a reading-related task differently from a speech processing task. It would be of interest, therefore, for future research to similarly examine the role of reading comprehension in participants' use of contextual information in spoken language processing (across the three populations tested).

It is possible, however, that the low-skilled readers in the current study were, in general, poor language users overall and that this led to their impaired prediction of upcoming language input. Although one cannot rule out this possibility, we note that a number of our findings speak against this possibility for the current study. First, we did not find any evidence that prediction ability was correlated with children's low-level language processing, that is, their phonological awareness. Second, we found that there was no interaction between participants' performance in the naming task and their prediction of upcoming language input. Thus, participants' word reading skills appear to uniquely interact with their prediction skills.

Another factor we wish to discuss here is possible general differences in processing speed across low- and high-skilled readers. Prediction of upcoming input is necessary to maintain a high reading speed (cf. Ehrlich \& Rayner, 1981), and the practice of reading may, in general, lead to more efficient processing in high-skilled readers. Alternatively, one reason why high-skilled readers are able to read at a faster pace may be that these participants are already generally faster at other tasks (e.g., motor control) relative to low-skilled readers, potentially due to non-linguistic individual differences between participants (e.g., socioeconomic differences). We suggest that this is unlikely because all children in the current study came from middle-class families and had similar exposure to literacy (i.e., number of months of schooling). This highlights the need for further investigation into the reasons why some children are more advanced readers relative to the others and whether these reasons might also underlie high-skilled readers' improved prediction of upcoming spoken language input. Nevertheless, we note that there were no significant correlations between children's performance in the pseudo-word decoding task, naming task, and phonological awareness tasks and their prediction of upcoming spoken language input, speaking against a purely processing speed-based explanation of the differences between the high-skilled and low-skilled readers in the current study. We do, however, 
believe that multiple-mechanism accounts are required to provide a complete picture of predictive language processing (see Mani \& Huettig, 2013, for further discussion).

In conclusion, the current study found that 8-year-old children's ability to predict upcoming input in spoken language processing was closely bound to their real-word reading skills but not to their pseudo-word reading and phonological awareness. We suggested a number of reasons for such reading-related differences in children's spoken language processing, focusing principally on their phonological decoding skills and the possibility of sharpening pre-existing lexical representations through acquisition of orthographic representations for words. Although we found little evidence of a role for phonological decoding skills, the evidence was consistent with an interaction between children's expertise in whole-word recognition (i.e., their sight-word vocabulary) and children's prediction of upcoming language input. We suggest, based on this evidence, that skilled readers equipped with a larger sight-word vocabulary are supported by the orthographic representations of the words they know in their recognition of these words such that they are better able to predict information consistent with these words in upcoming spoken language input.

\section{References}

Adrian, J. A., Alegria, J., \& Morais, J. (1995). Metaphonological abilities of Spanish illiterate adults. International Journal of Psychology, 30, 329-353.

Altmann, G. T. M., \& Kamide, Y. (1999). Incremental interpretation at verbs: Restricting the domain of subsequent reference. Cognition, 73, 247-264.

Arias-Trejo, N., \& Plunkett, K. (2009). Lexical priming effects during infancy. Philosophical Transactions of the Royal Society B, 364 , 3633-3647.

Barron, R., \& Baron, J. (1977). How children get meaning from printed words. Child Development, 48, 587-594.

Borovsky, A., Elman, J., \& Fernald, A. (2012). Knowing a lot for one's age: Vocabulary skill and not age is associated with anticipatory incremental sentence interpretation in children and adults. Journal of Experimental Child Psychology, 112, 417-436.

Brady, S. A., \& Shankweiler, D. (Eds.). (1991). Phonological processes in literacy: A tribute to Isabelle Y. Liberman. Hillsdale, NJ: Lawrence Erlbaum.

Bruck, M., Genesee, F., \& Caravolas, M. (1997). A cross-linguistic study of early literacy acquisition. In B. Blachman (Ed.), Foundations of reading acquisition and dyslexia (pp. 145-162). Mahwah, NJ: Lawrence Erlbaum.

Bryant, P., \& Bradley, L. (1980). Why children sometimes write words which they do not read. In U. Frith (Ed.), Cognitive processes in spelling (pp. 355-370). London: Academic Press.

Buchanan, L., Westbury, C., \& Burgess, C. (2001). Characterizing semantic space: Neighborhood effects in word recognition. Psychonomic Bulletin and Review, 8, 531-544.

Chang, F., Dell, G. S., \& Bock, K. (2006). Becoming syntactic. Psychological Review, 113, 234-272.

Coltheart, M. (1978). Lexical access in simple reading tasks. In G. Underwood (Ed.), Strategies of information processing (pp. 151-216). London: Academic Press.

Cossu, G., Gugliotta, M., \& Marshall, J. C. (1995). Acquisition of reading and written spelling in a transparent orthography: Two non-parallel processes? Reading and Writing, 7, 9-22.

Dell, G. S., \& Chang, F. (2013). The P-chain: Relating sentence production and its disorders to comprehension and acquisition. Philosophical Transactions of the Royal Society B, 369. doi: http://dx.doi.org/10.1098/rstb.2012.0394.

DeLong, K., Urbach, T., \& Kutas, M. (2005). Probabilistic word pre-activation during language comprehension inferred from electrical brain activity. Nature Neuroscience, 8, 1117-1121.

Doctor, E. A., \& Coltheart, M. (1980). Phonological recoding in children's reading for meaning. Memory E Cognition, 80, $195-209$.

Ehri, L. C., \& Wilce, L. S. (1979). Does word training increase or decrease interference in a Stroop task? Journal of Experimental Child Psychology, 27, 352-364.

Ehrlich, S. E., \& Rayner, K. (1981). Contextual effects on word perception and eye movements during reading. Journal of Verbal Learning and Verbal Behavior, 20, 641-655.

Federmeier, K. D., \& Kutas, M. (1999). A rose by any other name: Long-term memory structure and sentence processing. Journal of Memory and Language, 41, 469-495.

Frith, U., Wimmer, H., \& Landerl, K. (1998). Differences in phonological recoding in German- and English-speaking children. Scientific Studies of Reading, 2, 31-54.

Frost, R., \& Katz, L. (1989). Orthographic depth and the interaction of visual and auditory processing in word recognition. Memory \& Cognition, 17, 302-310.

Goswami, U. (1993). Phonological skills and learning to read. Annals of the National Academy of Sciences of the United States of America, 682, 296-311.

Goswami, U., \& Bryant, P. E. (1990). Phonological skills and learning to read. Hillsdale, NJ: Lawrence Erlbaum.

Gough, P. B., \& Hillinger, M. L. (1980). Learning to read: An unnatural act. Bulletin of the Orton Society, 30, 179-196.

Gough, P. B., \& Tunmer, W. E. (1986). Decoding, reading, and reading disability. Remedial and Special Education, 7(1), 6-10.

Hatcher, P. J., Hulme, C., \& Ellis, A. W. (1994). Ameliorating early reading failure by integrating the teaching of reading and phonological skills: The phonological linkage hypothesis. Child Development, 65, 41-57.

Huettig, F., Singh, N., \& Mishra, R. K. (2011). Language-mediated visual orienting behavior in low and high literates. Frontiers in Psychology, 2, 285. 
Juel, C., Grifflth, P. L., \& Gough, P. B. (1986). Acquisition of literacy: A longitudinal study of children in first and second grade. Journal of Educational Psychology, 78, 243-255.

Kamide, Y., Altmann, G. T. M., \& Haywood, S. L. (2003). Prediction and thematic information in incremental sentence processing: Evidence from anticipatory eye movements. Journal of Memory and Language, 49, 133-156.

Kendeou, P., van den Broek, P. W., White, M. J., \& Lynch, J. S. (2009). Predicting reading comprehension in early elementary school: The independent contributions of oral language and decoding skills. Journal of Educational Psychology, 101, 765-778.

Kimura, Y., \& Bryant, P. E. (1983). Reading and writing in English and Japanese. British Journal of Developmental Psychology, 1, 129-144.

Kosmidis, M. K., Tsapkini, K., Folia, V., Vlahou, C., \& Kiosseoglou, G. (2004). Semantic and phonological processing in illiteracy. Journal of the International Neuropsychological Society, 10, 818-827.

Lukatela, K., Carello, C., Shankweiler, D., \& Liberman, I. Y. (1995). Phonological awareness in illiterates: Observations from SerboCroatian. Applied Psycholinguistics, 16, 463-487.

Mani, N., Durrant, S., \& Floccia, C. (2012). Activation of phonological and semantic codes in toddlers. Journal of Memory and Language, 66, 612-622.

Mani, N., \& Huettig, F. (2012). Prediction during language processing is a piece of cake-but only for skilled producers. Journal of Experimental Psychology: Human Perception and Performance, 38, 843-847.

Mani, N., \& Huettig, F. (2013). Towards a complete multiple-mechanism account of predictive language processing [commentary on Pickering \& Garrod]. Behavioral and Brain Sciences, 36, 365-366.

Mann, V. A., \& Liberman, I. Y. (1984). Phonological awareness and verbal short-term memory. Journal of Learning Disabilities, 17, 592-598.

McDonald, S. A., \& Shillcock, R. C. (2003). Low-level predictive inference in reading: The influence of transitional probabilities on eye movements. Vision Research, 43, 1735-1751.

Mirman, D., \& Magnuson, J. S. (2009). Dynamics of activation of semantically similar concepts during spoken word recognition. Memory \& Cognition, 37, 1026-1039.

Mishra, R. K., Singh, N., Pandey, A., \& Huettig, F. (2012). Spoken language-mediated anticipatory eye movements are modulated by reading ability: Evidence from Indian low and high literates. Journal of Eye Movement Research, 5(1), 1-10.

Morais, J., Cary, L., Alegria, J., \& Bertelson, P. (1979). Does awareness of speech as a sequence of phones arise spontaneously? Cognition, 7, 323-331.

Morais, J., Castro, S.-L., \& Kolinsky, R. (1991). La reconnaissance des mots chez les adultes illettrés. In R. Kolinsky, J. Morais, \& J. Segui (Eds.), La reconnaissance des mots dans les différentes modalités sensorielles: Etudes de psycholinguistique cognitive (pp. 59-80). Paris: Presses Universitaires de France.

Morais, J., Castro, S.-L., Scliar-Cabral, L., Kolinsky, R., \& Content, A. (1987). The effects of literacy on the recognition of dichotic words. Quarterly Journal of Experimental Psychology A, 39, 451-465.

Nation, K., Marshall, C. M., \& Altmann, G. T. M. (2003). Investigating individual differences in children's real-time sentence comprehension using language-mediated eye movements. Journal of Experimental Child Psychology, 86, 314-329.

Nation, K., \& Snowling, M. J. (1998a). Individual differences in contextual facilitation: Evidence from dyslexia and poor reading comprehension. Child Development, 69, 996-1011.

Nation, K., \& Snowling, M. J. (1998b). Semantic processing and the development of word recognition skills: Evidence from children with reading comprehension difficulties. Journal of Memory and Language, 39, 85-101.

Pattamadilok, C., Perre, L., Dufau, S., \& Ziegler, J. C. (2009). On-line orthographic influences on spoken language in a semantic task. Journal of Cognitive Neuroscience, 21, 169-179.

Perfetti, C. A., Goldman, S., \& Hogaboam, T. (1979). Reading skill and the identification of words in discourse context. Memory E Cognition, 7, 273-282.

Petersson, K. M., Reis, A., Askelof, S., Castro-Caldas, A., \& Ingvar, M. (2000). Language processing modulated by literacy: A network analysis of verbal repetition in literate and illiterate subjects. Journal of Cognitive Neuroscience, 12, 364-382.

Pickering, M. J., \& Garrod, S. (2007). Do people use language production to make predictions during comprehension? Trends in Cognitive Sciences, 11, 105-110.

Reis, A., \& Castro-Caldas, A. (1997). Illiteracy: A bias for cognitive development. Journal of the International Neuropsychological Society, 3, 444-450.

Reis, A., Petersson, K. M., Castro-Caldes, A., \& Ingvar, M. (2001). Formal schooling influences two- but not three-dimensional naming skills. Brain and Cognition, 47, 397-411.

Saslow, M. G. (1967). Latency for saccadic eye movement. Journal of the Optical Society of America, 57, 1030-1033.

Schwanenflugel, P. J., \& Shoben, E. J. (1985). The influence of sentence constraint on the scope of facilitation for upcoming words. Journal of Memory and Language, 24, 232-252.

Seidenberg, M. S., Waters, G. S., Barnes, M. A., \& Tanenhaus, M. K. (1984). When does irregular spelling or pronunciation influence word recognition? Journal of Verbal Learning and Verbal Behavior, 23, 383-404.

Seidenberg, M. S., \& McClelland, J. L. (1989). A distributed, developmental model of word recognition and naming. Psychological Review, 96, 523-568.

Serniclaes, W., Ventura, P., Morais, J., \& Kolinsky, R. (2005). Categorical perception of speech sounds in illiterate adults. Cognition, $98,835-844$.

Silva, C., Faísca, L., Ingvar, M., Petersson, K. M., \& Reis, A. (2012). Literacy: Exploring working memory systems. Journal of Clinical and Experimental Neuropsychology, 34, 369-377.

Smith, A., Monaghan, P., \& Huettig, F. (2013). Modelling the effects of formal literacy training on language mediated visual attention. In M. Knauff, M. Pauen, N. Sebanz, \& I. Wachsmuth (Eds.), Proceedings of the 35th annual meeting of the Cognitive Science Society (CogSci 2013) (pp. 3420-3425). Austin, TX: Cognitive Science Society.

Styles, S. J., \& Plunkett, K. (2011). Early links in the early lexicon. In G. Gaskell \& P. Zwitserlood (Eds.), Lexical representation: A multi-disciplinary approach (pp. 51-88). Berlin: Mouton de Gruyter.

Van Berkum, J. J. A., Brown, C. M., Zwitserlood, P., Kooijman, V., \& Hagoort, P. (2005). Anticipating upcoming words in discourse: Evidence from ERPs and reading times. Journal of Experimental Psychology: Learning, Memory, and Cognition, 31, $443-467$. 
Wagner, R. K., \& Torgesen, J. K. (1987). The nature of phonological awareness and its causal role in the acquisition of reading skills. Psychological Bulletin, 101, 192-212.

Wagner, R. K., Torgesen, J. K., \& Rashotte, C. A. (1994). Development of reading-related phonological processing abilities: New evidence of bidirectional causality from a latent variable longitudinal study. Developmental Psychology, 30, 73-87.

Wicha, N. Y. Y., Moreno, E. M., \& Kutas, M. (2004). Anticipating words and their gender: An event-related brain potential study of semantic integration, gender expectancy, and gender agreement in Spanish sentence reading. Journal of Cognitive Neuroscience, 16, 1272-1288.

Ziegler, J. C., \& Ferrand, L. (1998). Orthography shapes the perception of speech: The consistency effect in auditory word recognition. Psychonomic Bulletin and Review, 5, 683-689. 